\title{
Three-Dimensional Visualization of the Crack-Growth Behavior of Nano-Silver Joints During Shear Creep
}

\author{
YANSONG TAN,${ }^{1}$ XIN LI, ${ }^{2,3}$ GANG CHEN,${ }^{1}$ YUNHUI MEI, ${ }^{2,3}$ \\ and XU CHEN ${ }^{1,4}$
}

1.-School of Chemical Engineering and Technology, Tianjin University, Tianjin 300072, People's Republic of China. 2.-Tianjin Key Laboratory of Advanced Joining Technology, Tianjin 300072, People's Republic of China. 3.-School of Materials Science and Engineering, Tianjin University, Tianjin 300072, People's Republic of China. 4.—e-mail: xchen@tju.edu.cn

\begin{abstract}
Evolution of creep damage in nano-silver sintered lap shear joints was investigated at $325^{\circ} \mathrm{C}$. Non-destructive $\mathrm{x}$-ray three-dimensional (3D) visualization clearly revealed the crack-growth behavior of the joint; this could be divided into three stages. In the initial stage, little development of cracks occurred. In the second stage, cracks propagated at a consistent rate. In the final stage, rapid extension of the cracks led directly to fracture of the joint. Three-dimensional volume-rendered images and fractographic analysis showed that the growth of macroscopic initial cracks at the interfaces dominated the creep fracture process. Initial failure of nano-silver sintered lap shear joints often occurred at interfacial nano-silver paste layers. Both the size and position of the initial interfacial cracks had significant effects on the final creep failure of the joints, and higher stresses led to greater porosity and earlier failure.
\end{abstract}

Key words: X-ray 3D visualization, nano-silver joint, creep, crack

\section{INTRODUCTION}

Increasing health concerns over the toxicity of $\mathrm{Pb}$ in eutectic $\mathrm{Pb}-\mathrm{Sn}$ solders have prompted the development of new interconnection materials for electronic packaging. ${ }^{1-3}$ As substitutes for traditional $\mathrm{Pb}-\mathrm{Sn}$ solder, lead-free solder alloys and conductive adhesives are commonly used as die-attach materials for use at operating temperatures below $300^{\circ} \mathrm{C}^{4}$ In recent decades, with the appearance of high-power-density systems, for example switching-mode power converters, laser diodes, high-brightness light-emitting diodes, and radiofrequency modules, microelectronic joints are typically exposed to aggressive thermomechanical cycling (TMC) conditions with high temperatures and large strain during service. ${ }^{5}$ Traditional solders have practical limitations in meeting the demanding requirements for large heat dissipation and wide operating temperatures. ${ }^{6-9}$ Superior lead-free

(Received April 2, 2014; accepted November 24, 2014;

published online December 9, 2014) die-attach materials are urgently needed for the power electronics industry. ${ }^{10,11}$ Nano-silver paste, a novel lead-free interconnection material that can be used in wide-band-gap semiconductors working at high temperatures because of its high thermal conductivity, electrical conductivity, and melting point, is gradually becoming an alternative to traditional solder alloys and conductive adhesives. ${ }^{3,12-15}$

Studies have shown that the mechanism of fracture of the die-attached joint is crucially important for evaluating the mechanical reliability of electronic assemblies. ${ }^{16-18}$ It has been reported by investigators that creep fracture is a process of nucleation, growth, and coalescence of cavities along the grain boundary in a localized, inhomogeneous manner. ${ }^{19}$ Creep crack growth is one of the most likely modes of failure of a joint when power electronics are working at elevated temperatures. ${ }^{20,21}$ The creep behavior of traditional solders have been studied. ${ }^{22-26}$ It was found that one or several major cracks initiated and propagated at the interface between the substrate and solder layer during creep loading, leading to final fracture of the 
die-attached joint. ${ }^{18}$ Research has led to a sound understanding of the mechanical responses of nano-silver paste. ${ }^{9-15} \mathrm{Li}$ et al. used the Arrhenius power-law model to study the creep properties of nano-silver lap shear joints. ${ }^{4}$ By observation of typical fracture surfaces, the porous structure of the joint and linking of the micro-voids during creep shear testing were documented. However, this study was largely limited to examination of twodimensional fracture surfaces, and macro-stress or macro-strain could not precisely characterize the creep behavior of nano-silver sintered joints. So far, no studies of the evolution of non-destructive creep damage have been conducted for nano-silver sintered lap shear joints. It has been reported by many investigators that for any structure, it is the geometry, scale, and nature of the structure in all three dimensions that determines the properties of the structure. ${ }^{27-29}$ Thus, three-dimensional (3D) characterization of both the structure and the damage processes is essential and of great value. ${ }^{30,31}$

The purpose of this work was to characterize creep crack growth by use of x-ray computer tomography (XCT), a non-destructive technique for detection of damage. Observation of creep crack growth is expected to promote better understanding of the mechanism of fracture of nano-silver sintered joints.

\section{EXPERIMENTAL}

Silver paste, composed of spherical nano-scale silver particles and organic components, ${ }^{10}$ was sandwiched between two Ag-electroplated copper substrates and sintered to form the nano-silver joint specimens. Figure 1 shows the recommended sintering profile. A high sintering temperature of $280^{\circ} \mathrm{C}$ outgassed the organic components and subsequently densified the joint. A well-prepared specimen with an area of $2 \mathrm{~mm} \times 1 \mathrm{~mm}$ and a bond line thickness of $50 \mu \mathrm{m}$ is shown in Fig. 2. The experiments were conducted on a micro-uniaxial fatigue testing system (MUF-1020), as shown in Fig. 3, at $325^{\circ} \mathrm{C}$. The shear strain was determined by dividing the joint displacement by the lapped nano-silver joint thickness. $^{32-34}$

X-ray radiographs were captured by use of a Y. Cougar-Feinfocus $x$-ray imaging system. The $\mathrm{x}$-ray system is shown in Fig. 4 . When the tungsten microfocus x-ray source was powered at $110 \mathrm{kV}$ and $2.5 \mathrm{~W}$, x-rays emitted from the target penetrated the specimen and arrived at an amorphous-silicon flatpanel image detector. ${ }^{35}$ The detector worked by converting the x-rays that struck its surface into light, and then turning the light into electronic data that a computer could display as a high-quality digital image. Because defects such as cracks and cavities could not absorb $x$-rays, the rays penetrated the defects before being received by the x-ray detector, leading to a lighter gray scale, so the defects could be imaged. ${ }^{36-38} \mathrm{~A}$ series of 540 images, taken at angular increments of $2 / 3^{\circ}$, were acquired at a

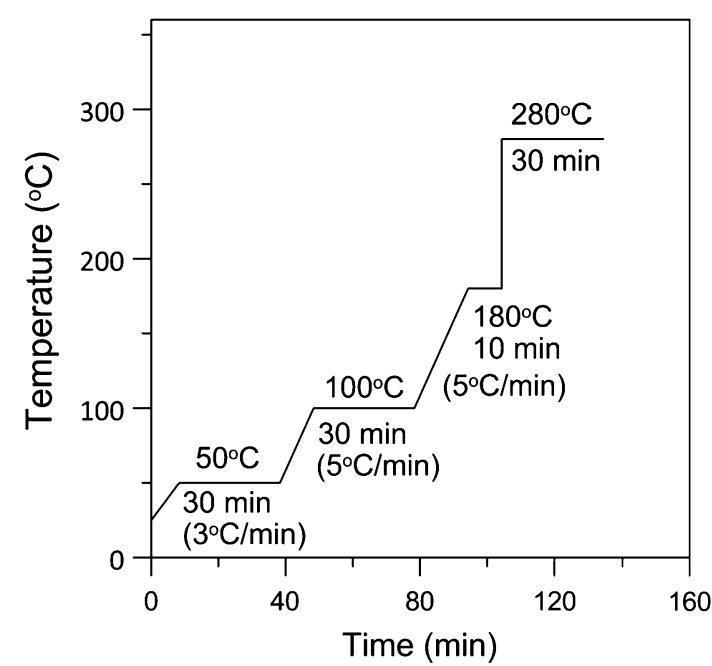

Fig. 1. Sintering profile for nano-silver paste.

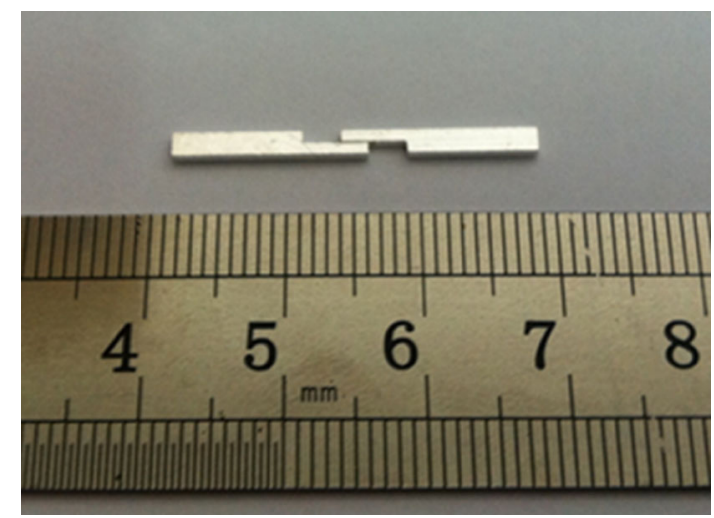

Fig. 2. Single lap shear joint with sintered nano-silver paste.

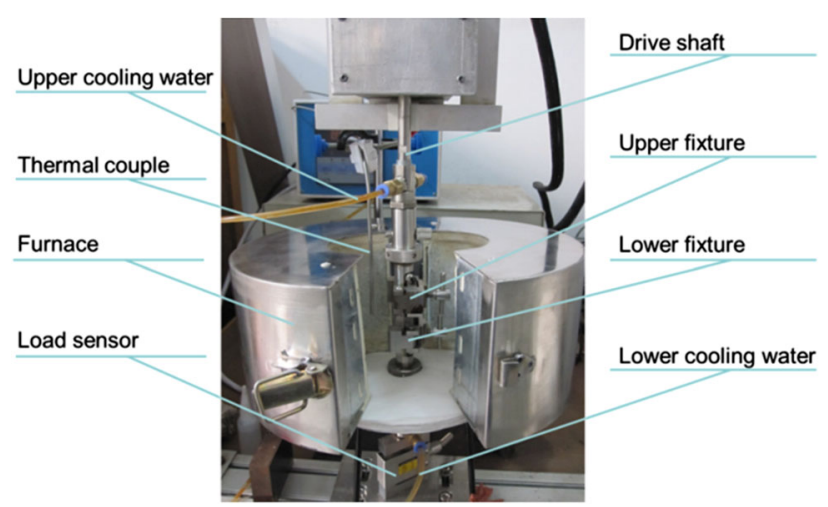

Fig. 3. Testing apparatus.

specimen-source distance of $9.5 \mathrm{~mm}$ and a specimen-detector distance of $190 \mathrm{~mm}$. The spatial resolution of the Y. Cougar-Feinfocus imaging system was determined by x-ray tube voltage and current, the x-ray magnification, and detection efficiency. An amorphous silicon flat-panel image detector was equipped with $1004 \times 620$ pixels of $127 \times 127 \mu \mathrm{m}$ 
pixel size. ${ }^{29}$ Two and three-dimensional visualization of nano-silver sintered lap-shear joints was performed by use of VGstudio 2.1 software, as shown in Fig. 5a. The blue, green, and red planes slice the joint in three dimensions. The left view, front view, and top view of the joint, with the colored planes, are shown in Fig. 5b, c, and d, respectively.

The specimen was loaded as shown in Fig. 6a. After removal of $\mathrm{Cu}$ substrates from the specimen, the nano-silver paste layers in the 3D image were seen (Fig. 6b). The nano-silver paste layers were divided into two parts, two interfacial nano-silver paste layers and internal nano-silver paste layers. The left interfacial nano-silver paste layer (left interface) was obtained from the left view of the 3D image, and the right interfacial nano-silver paste layer (right interface) was obtained from the right view of the 3D image, as shown in Fig. 6a. Figure 6c shows the left view of the nano-silver paste layers of specimen 1; this is an image of the left interfacial nano-silver paste layer after constant loading of $2 \mathrm{MPa}$ for $21 \mathrm{~h}$. The cracks were identified from the different gray scale intensities of the materials. Figure $6 \mathrm{~d}$ shows the image of the nano-silver paste layers (left view) as reconstructed by VGStudio 2.1. Compared with Fig. 6c and d showed the crack shape, size, and position clearly. The porosity of the interfacial nano-silver paste layer was $8.9 \%$, which was calculated by Image-Pro plus 6.0 , as shown in Fig. 6e. By reducing the opacity of the nano-silver paste from $100 \%$ to $20 \%$, the corresponding transparent left view of the nano-silver paste layers was obtained, as shown in Fig. 6f, in which internal cracks are marked by red arrows. The discussion below is based on the 3D tomographic reconstructed images.

\section{RESULTS AND DISCUSSION}

The crack-growth behavior of the nano-silver sintered lap shear joint was revealed by analysis of the creep strain-time relationship, XCT visualization of the damage process, and calculation of the porosity of interfacial nano-silver paste layers. The results from three representative specimens with different initial defects were selected for detailed discussion; specimens 1 and 2 were tested at a stress of $2 \mathrm{MPa}$, and specimen 3 at $3 \mathrm{MPa}$.

\section{High-Temperature Creep of Nano-Silver Sintered Joint}

\section{Creep Crack Growth}

The creep strain-time curve for specimen 1 is shown in Fig. 7. This curve had the common features of a typical creep process with three stages: the transient creep stage, the steady-state creep stage, and the accelerating creep stage. At different times, illustrated for specimen 1 in Fig. 7 from (a) to (e), the images of nano-silver paste layers were taken by x-ray observation; the results are shown in Fig. 8. The cracks in left interfacial nano-silver paste layer (interfacial cracks) are presented in left view, and the cracks in the internal nano-silver paste layers (internal cracks) are shown in transparent left view.

During the transient creep stage slight plastic deformation occurred, because of the softness of the nano-silver paste layers. Thus there was an increase in shear strain for specimen 1 from (a) to (b) in Fig. 7. In this stage, little development of the cracks was observed, as indicated by the red arrows in Fig. 8a and $b$. At the same time, several new cracks initiated

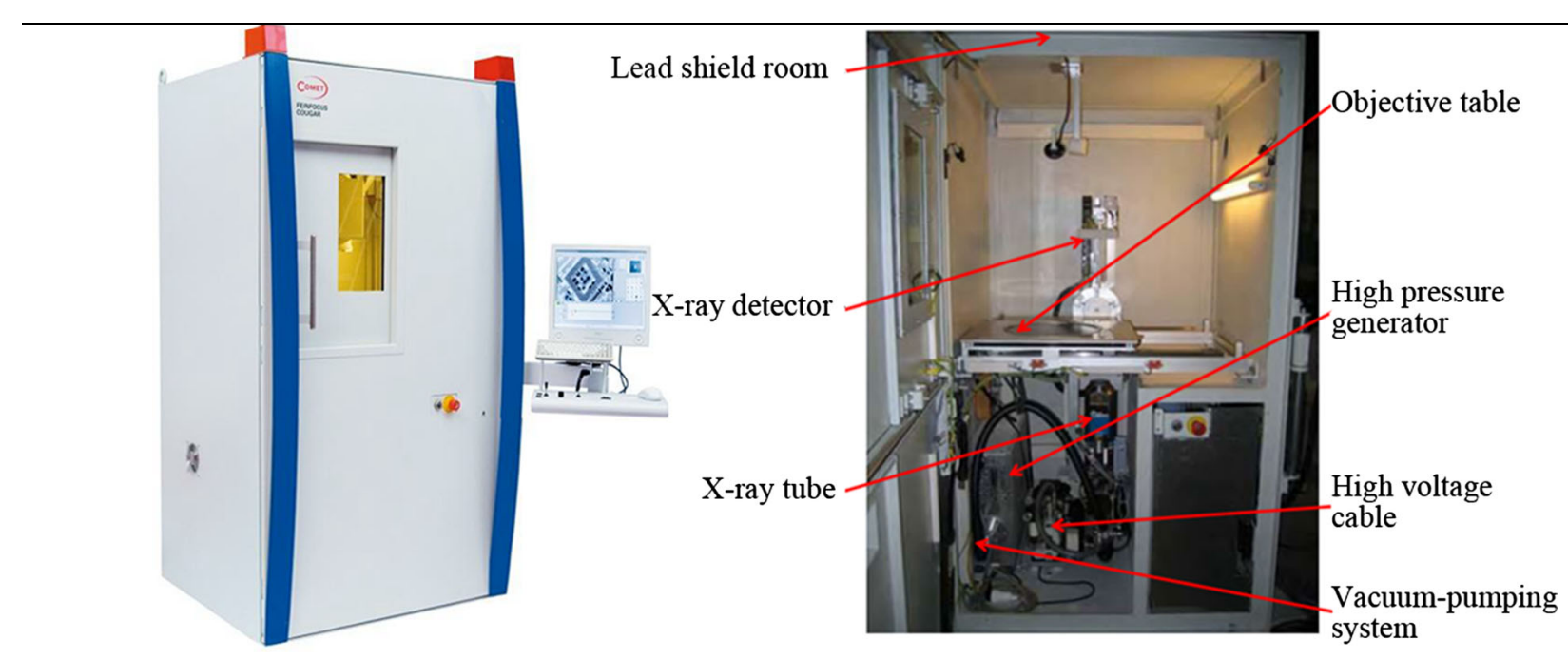

Fig. 4. The x-ray system. 


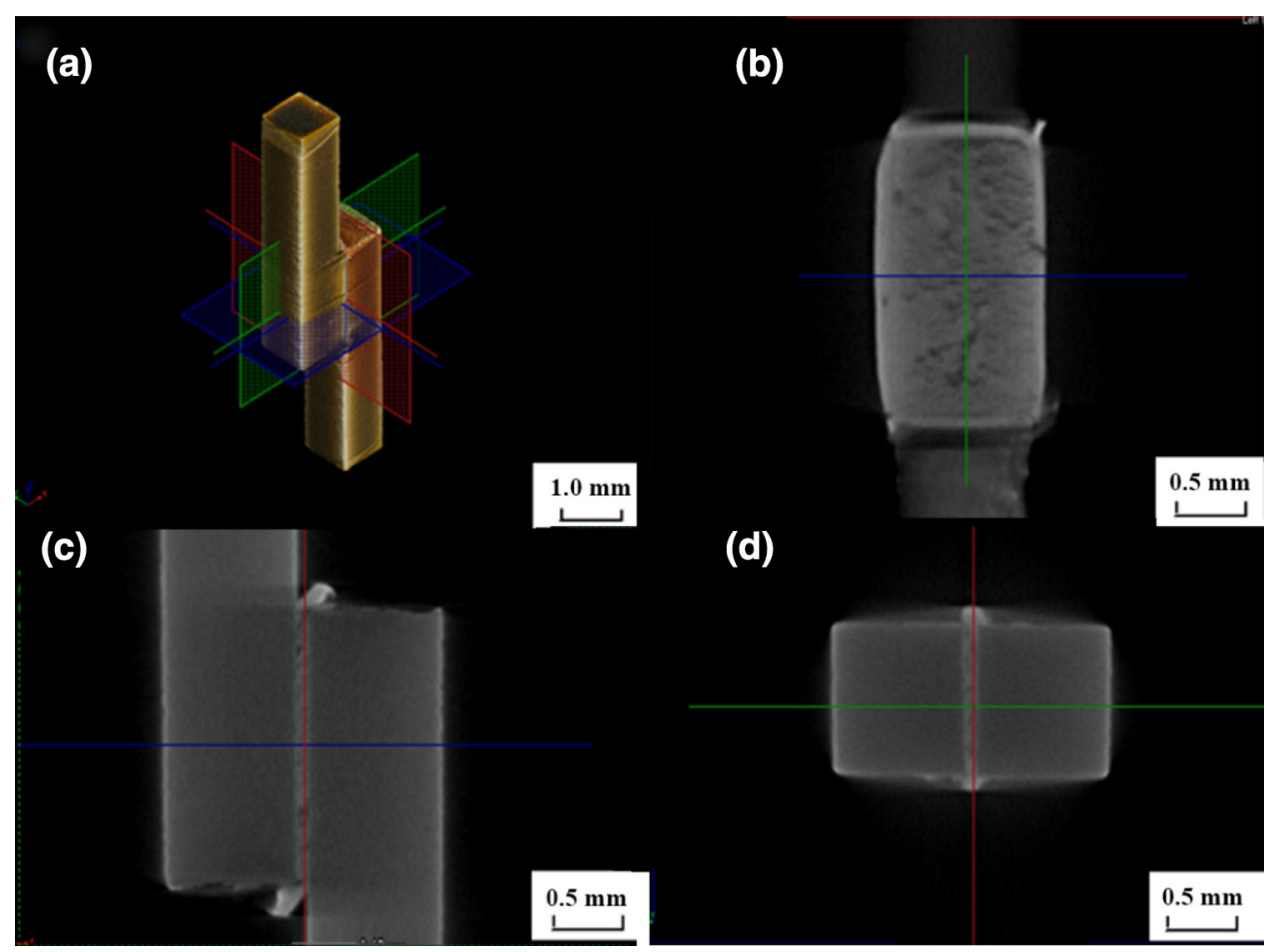

Fig. 5. (a) 3D visualization of the nano-silver sintered joint. (b), (c) and (d) are the left view, front view, and top view, respectively, of the corresponding cross-sections. Colored lines in (b), (c) and (d) correspond to planes with the same color as in (a).
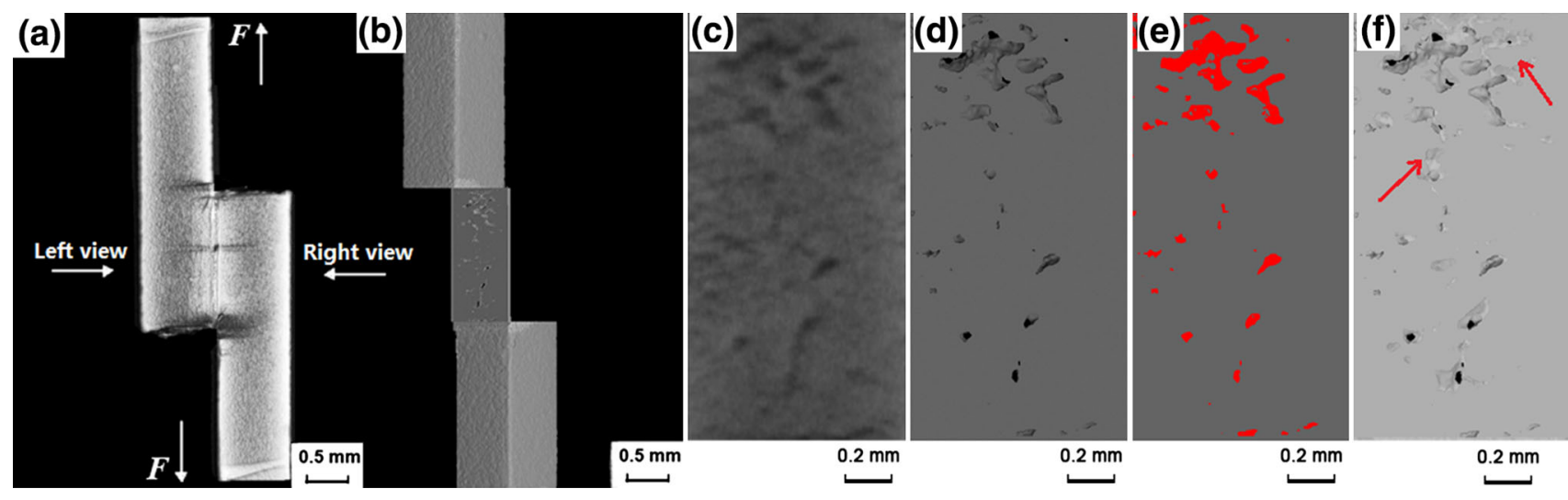

Fig. 6. (a) 3D image of nano-silver sintered lap shear joint; (b) 3D image of nano-silver paste layers from the perspective of 45 deg; (c) left view of nano-silver paste layers; (d) the reconstructed 3D image of the left interfacial nano-silver paste layer; (e) porosity calculation for Fig. 6(d) by Image-Pro plus 6.0; (f) the corresponding transparent left view (3D) of the nano-silver paste layers in Fig. 6(b); internal cracks are clearly apparent in Fig. 6(f) (red arrows) (Color figure online).

both at the interfaces and inside the sintered nanosilver joint (as indicated by the pink arrows in Fig. 8b, for example). With increasing creep strain, the strain hardening of the silver accelerated and finally reached saturation. ${ }^{39}$ The strain rate decreased to a constant value, and the nano-silver paste layers reached the steady-state creep stage corresponding to Fig. $8 \mathrm{~b}$, c, and d. In this stage, new cracks continued to initiate at the interface. At the same time, old cracks expanded in all directions, and thus many isolated cracks connected with one another to form continuous cracks. In the tertiary creep stage, the rapid strain rate could be attributed to rapid growth of the cracks. At this stage, the crack growth rate is an increasing function of the percentage of cracks. As shown in Fig. 8d and e, because of the high rate of propagation, a large number of cracks connected with one another, some of which developed into penetrated cracks, as indicated by the green arrows in Fig. 8d and e. The cracks further merged into a large fracture area and ultimately led to final fracture of the joint within a short time. In addition, the cracks inside the nano-silver paste layers mainly extended along the longitudinal direction, which was 


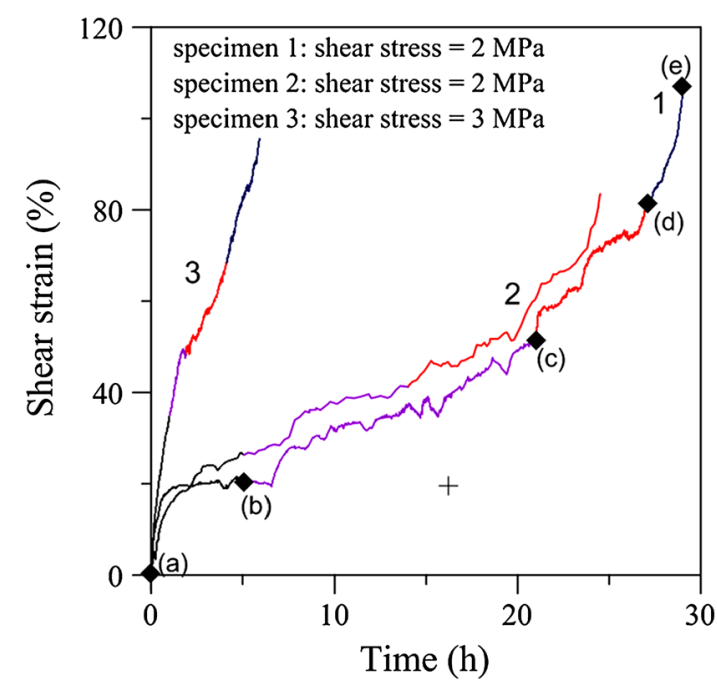

Fig. 7. Shear strain-time relationship for three specimens tested at $325^{\circ} \mathrm{C}$; specimens 1 and 2 were tested at a stress of $2 \mathrm{MPa}$, specimen 3 at a stress of $3 \mathrm{MPa}$; the black, red, and blue curves indicate transient creep stage, steady-state creep stage, and accelerating creep stage, respectively (Color figure online). parallel to the load direction in the transient creep stage, as indicated by the pink boxes in Fig. 8b, and turned into the longitudinal direction and the perpendicular direction in the steady-state creep and accelerating creep stages.

\section{Cross-Sectional Cracking Patterns}

For further analysis, the defects distributed within the entire nano-silver paste layers are presented as 3D volume-rendered images in Fig. 9. As shown in Fig. 9a, Initial cracks larger than $50 \mu \mathrm{m}$ were formed during sintering of the nano-silver sintered lap shear joint; these were the passages of volatilized organic components of the nano-silver paste. During creep, these cracks were important in strain localization around the regions of the cracks, thus these initial cracks grew gradually with creep time. From Fig. 9c and d it was concluded that with continued growth of these cracks, their locations constantly became closer to each other, which further increased the accumulated strain and promoted the interlinkage, thus accelerating the creep

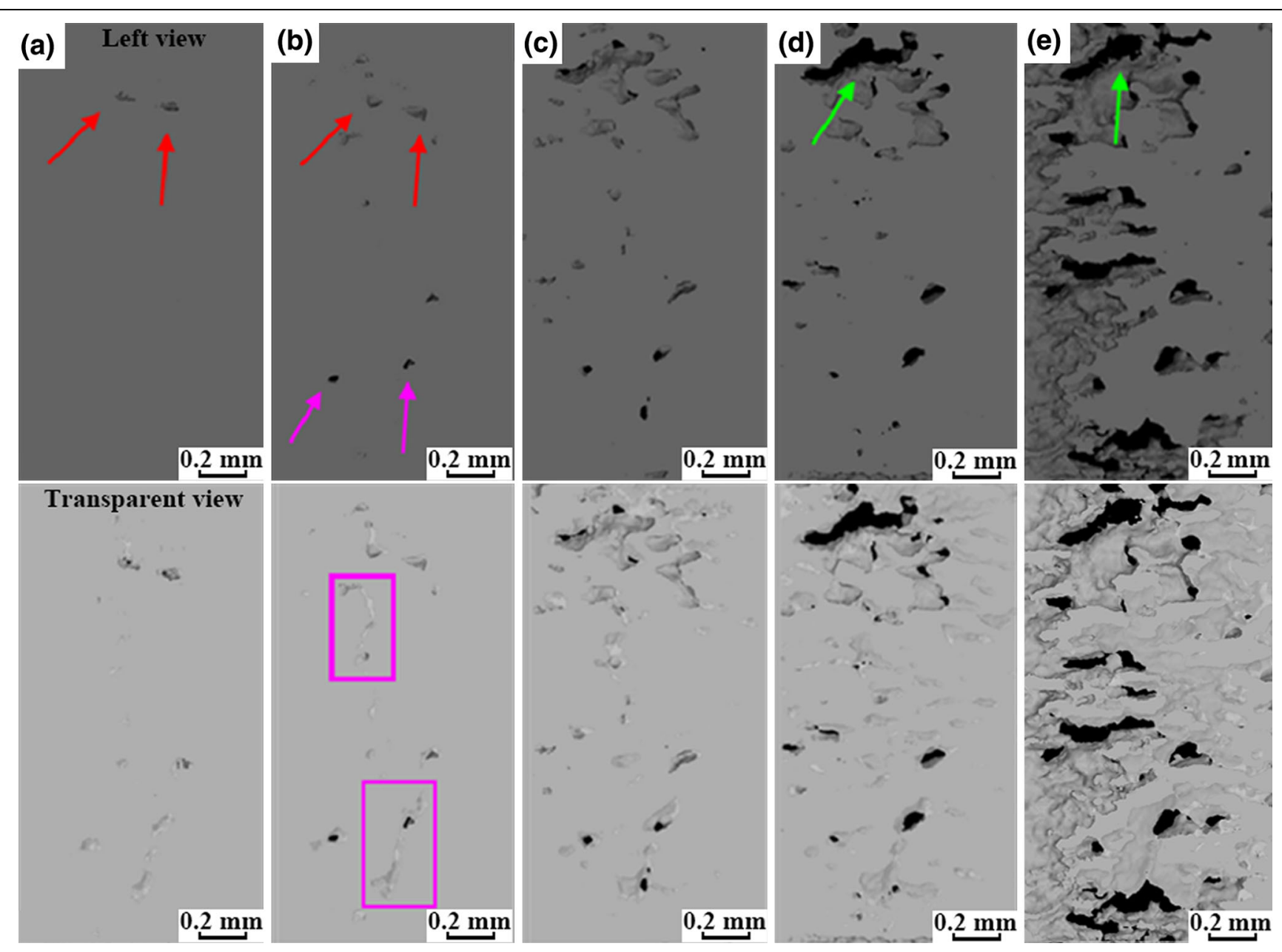

Fig. 8. Cross-section images of one of the interfacial nano-silver paste layers (left view) and the corresponding transparent left view (3D) of nano-silver paste layers after (a) $0 \mathrm{~h}$, (b) $5 \mathrm{~h}$, (c) $21 \mathrm{~h}$, (d) $27 \mathrm{~h}$, and (e) $29.3 \mathrm{~h}$ during creep; the red arrows in (a) and (b) point to initial cracks in the interfacial nano-silver paste layer; the purple arrows in (b) show new cracks initiated in the interfacial nano-silver paste layer; the purple boxes in (b) show the cracks in internal nano-silver paste layers; the cracks indicated by green arrows in (c) and (d) are through cracks. 

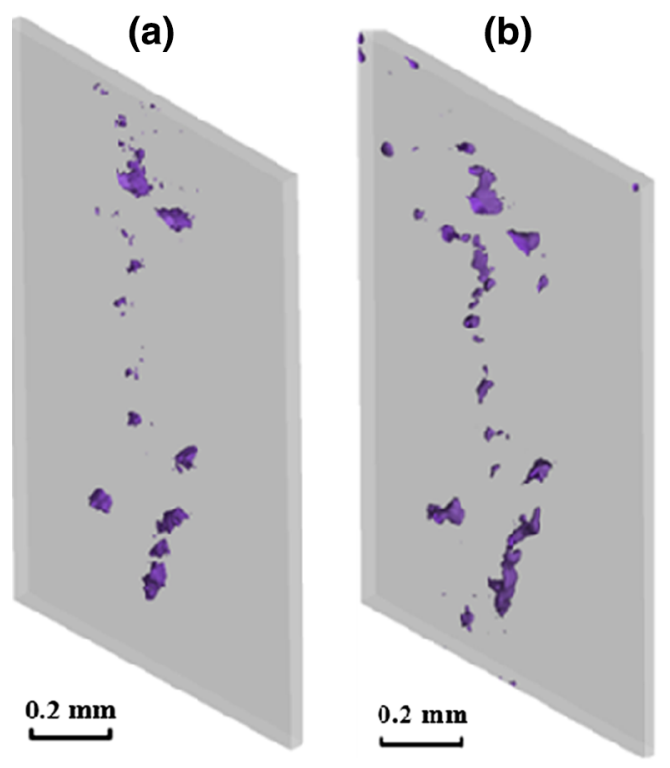

(c)

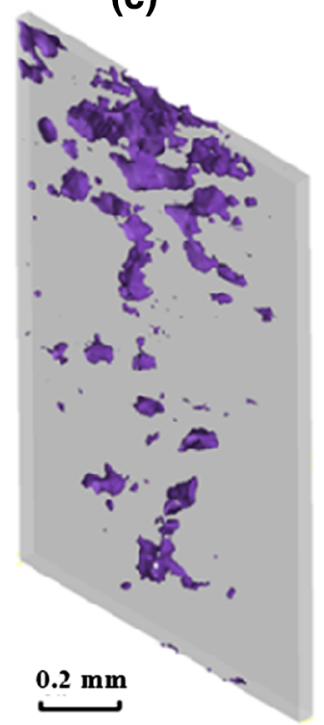

(d)

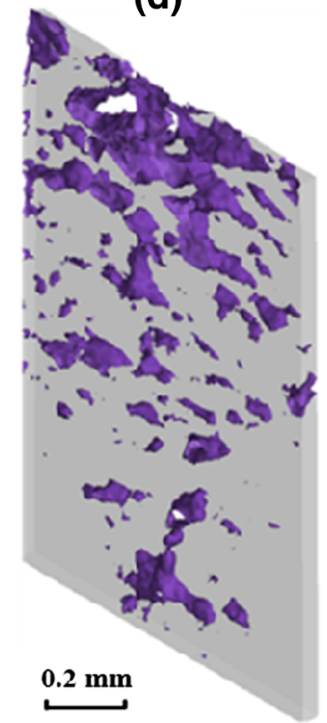

(e)

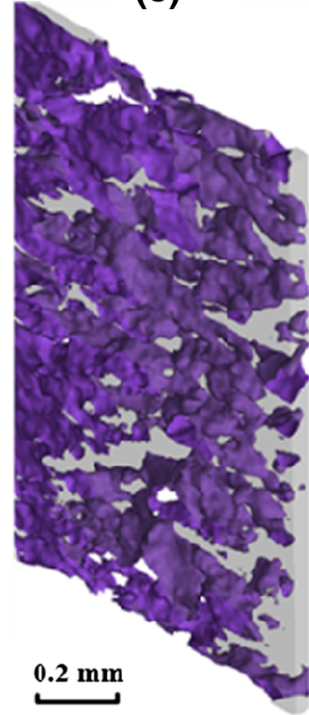

Fig. 9. Three-dimensional volume-rendered images of nano-silver paste layers at (a) $0 \mathrm{~h}$, (b) $5 \mathrm{~h}$, (c) $21 \mathrm{~h}$, (d) $27 \mathrm{~h}$, and (e) $29.3 \mathrm{~h}$ during creep.

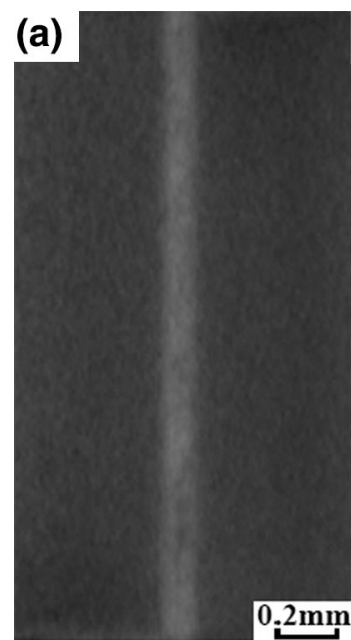

(b)

(c)

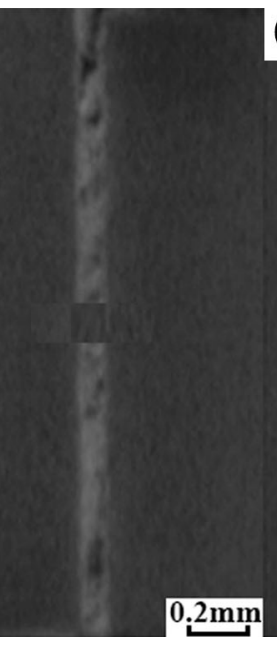

(d)

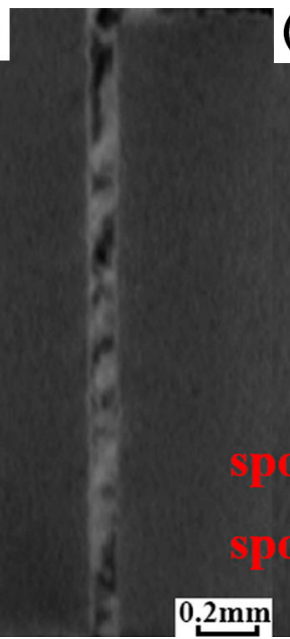

(e)

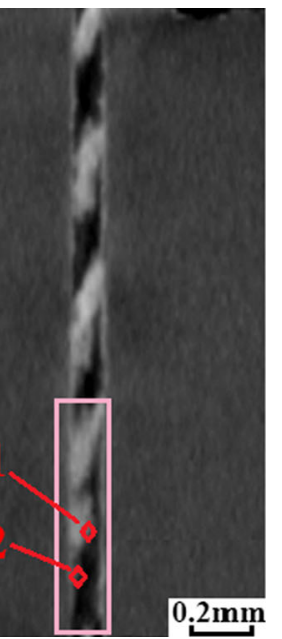

Fig. 10. Front view images of specimen 1 at (a) 0 h, (b) 5 h, (c) 21 h, (d) 27 h, and (e) $29.3 \mathrm{~h}$ during creep; spot 1 indicates the internal nanosilver paste layer; spot 2 indicates the interfacial nano-silver paste layer.

life failure. ${ }^{40,41}$ Comparison of Figs. 8 and 9 reveals that the size of the interfacial cracks is smaller than that of the internal cracks. However, the growth rate of the interfacial cracks is significantly greater than that of the internal cracks. Front view images of a nano-silver sintered lap shear joint during creep are shown in Fig. 10. Figure 10 shows that the process of crack growth is from internal nano-silver paste layers to interfacial nano-silver paste layers. It was observed that initial fracture occurred at the interfaces of the specimen, as shown in the pink box in Fig. 10e. Therefore, the initial crack growth at the interfaces dominated the creep fracture process of nano-silver sintered lap shear joints.

Typical fracture surfaces of specimen 1 at $325^{\circ} \mathrm{C}$ and $2 \mathrm{MPa}$ are shown in Fig. 11. No significant plastic flow was found in the loading direction.
Figure $11 \mathrm{a}$ is the overview of the cross-section marked by the pink box in Fig. 10, and Fig. 11b is a detailed view of the fracture section marked by the red box in Fig. 11a (spot 1 is the microstructure of the internal nano-silver paste layer, and spot 2 is the microstructure of the interfacial nano-silver paste layer). Figure 11c and $d$ are detailed views of spot 1; Fig. $11 \mathrm{e}$ and $\mathrm{f}$ are detailed views of spot 2 , in which some microscale voids interlock with one another. These microscale voids were the sources of crack growth. Studies have shown that nano-silver sintered lap shear joints are a type of porous structure with initial microscale size sintered voids. ${ }^{6,7,10-15}$ Under constant loading, these microscale voids around the initial cracks gradually increased in size and merged along grain boundaries. Finally they interlocked with one another, 

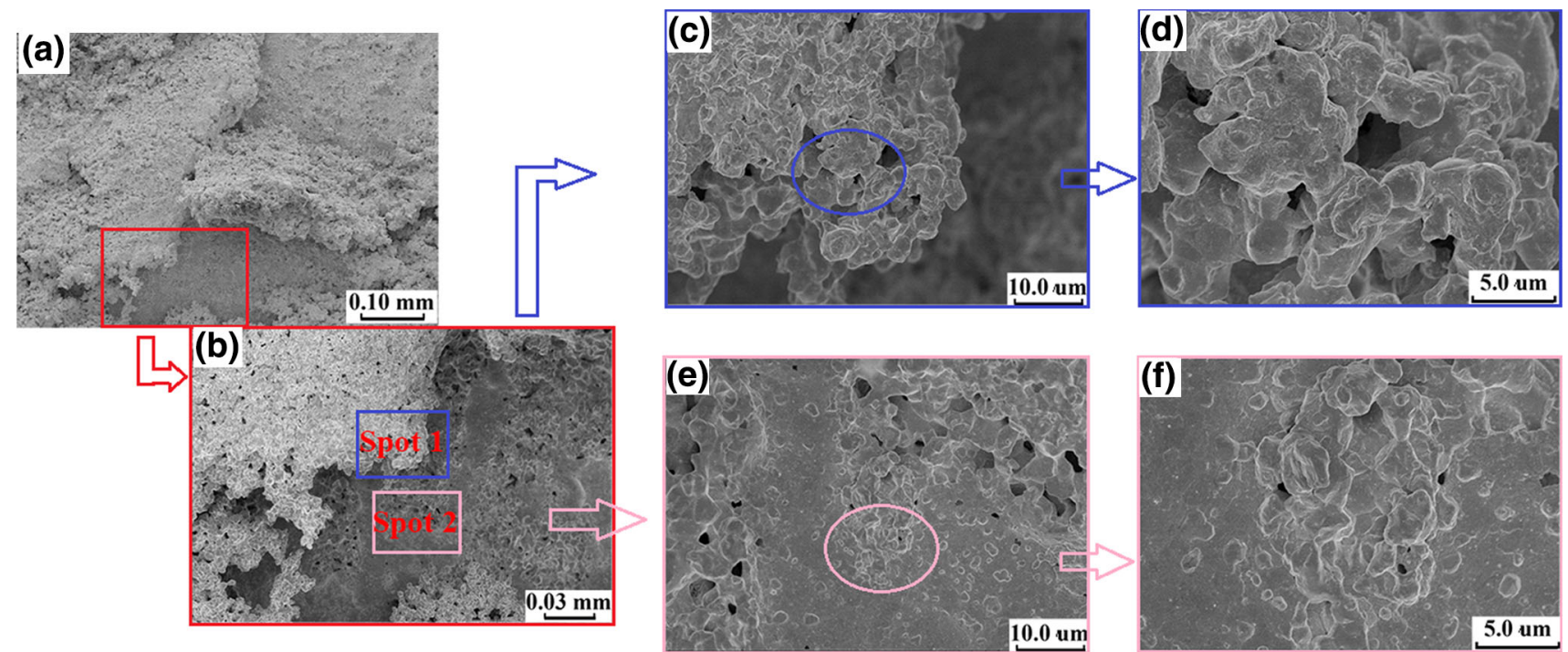

Fig. 11. SEM images of the fracture section of specimen 1. (a) Overview of the cross-section marked by the pink box in Fig. 10; (b) detailed view of the fracture section marked by the red box in (a) (spot 1 is the microstructure of the internal nano-silver paste layer, spot 2 is the microstructure of the interfacial nano-silver paste layer, as shown in Fig. 10e); (c) and (d) are detailed views of spot 1; (e) and (f) are detailed views of spot 2.

resulting in growth of the initial cracks. The weakness of the interfacial nano-silver paste layers promoted concentration of stress at the interfaces, resulting in acceleration of the microscale void growth and coalescence at the interfaces. ${ }^{42}$ Hence the initial cracks propagated to the interfaces faster than they did in other directions of the nano-silver paste layers. Microstructure analysis further verified that, because of the weakness of the interfacial nano-silver paste layers, initial fracture occurred at the interfacial silver paste layers.

\section{Effect of Initial Cracks on Creep}

As mentioned above, the initial cracks varied from one nano-silver sintered joint to another. Studies have shown that porosity causes weakening of the joint, resulting in loss in ductility because of strain localization around the region of the defects and reduction of the reliability of the joint. ${ }^{43}$ To study the effect of initial cracks on creep, specimens 1 and 2 with different initial cracks were tested under the same stress of $2 \mathrm{MPa}$. The porosities of the two interfacial nano-silver paste layers were calculated at different creep times. Figure 12 shows the interfacial porosity of these two specimens as a function of creep time. The initial porosities of the left and right interfaces were $0.18 \%$ and $0.27 \%$, respectively, for specimen 1 , but $0.98 \%$ and $0.03 \%$, respectively, for specimen 2 . In other words, there was little difference in porosity between the two interfaces of specimen 1 , but a substantial difference in porosity between the two interfaces of specimen 2. During creep, the porosities at the two interfaces of specimen 1 increased synchronously, whereas those of specimen 2 increased with great differences. In specimen 1 , cracks in the nano-silver

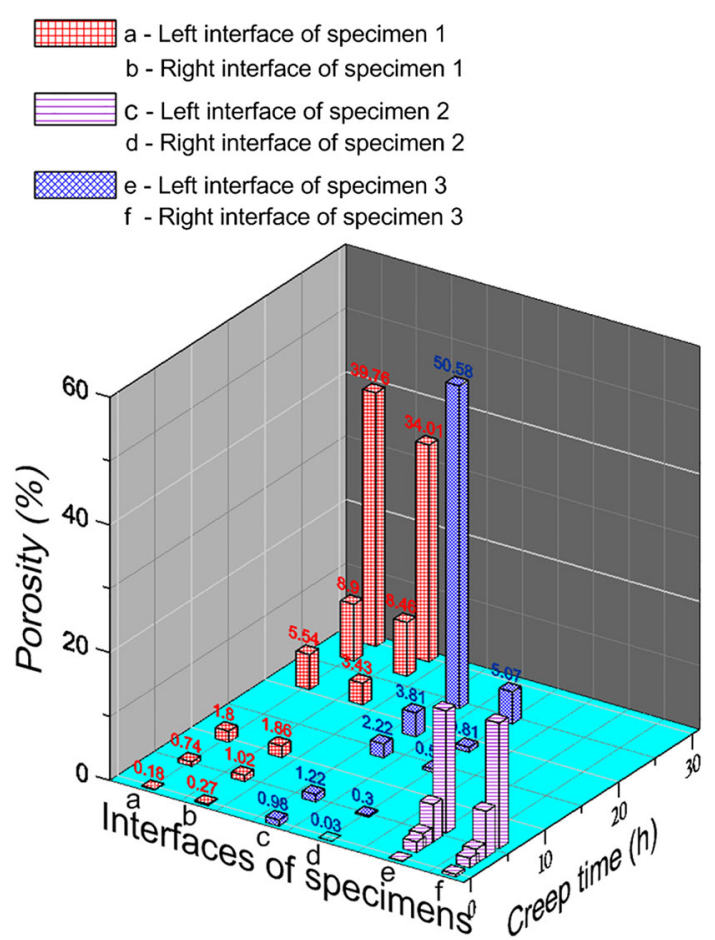

Fig. 12. Porosity of the interfacial nano-silver paste layers of the tested three specimens; the porosity of specimens 1 and 2 was calculated at different creep time as shown in the figure; the porosity of specimen 3 was calculated at different creep times of $0 \mathrm{~h}, 1.9 \mathrm{~h}$, $2.8 \mathrm{~h}, 4.1 \mathrm{~h}$, and $5.9 \mathrm{~h}$.

paste layers grew toward the two interfaces simultaneously, while in specimen 2 , owing to more noticeable initial cracks at the left interface than at the right interface, cracks inside the nano-silver paste layers grew more rapidly toward the left 


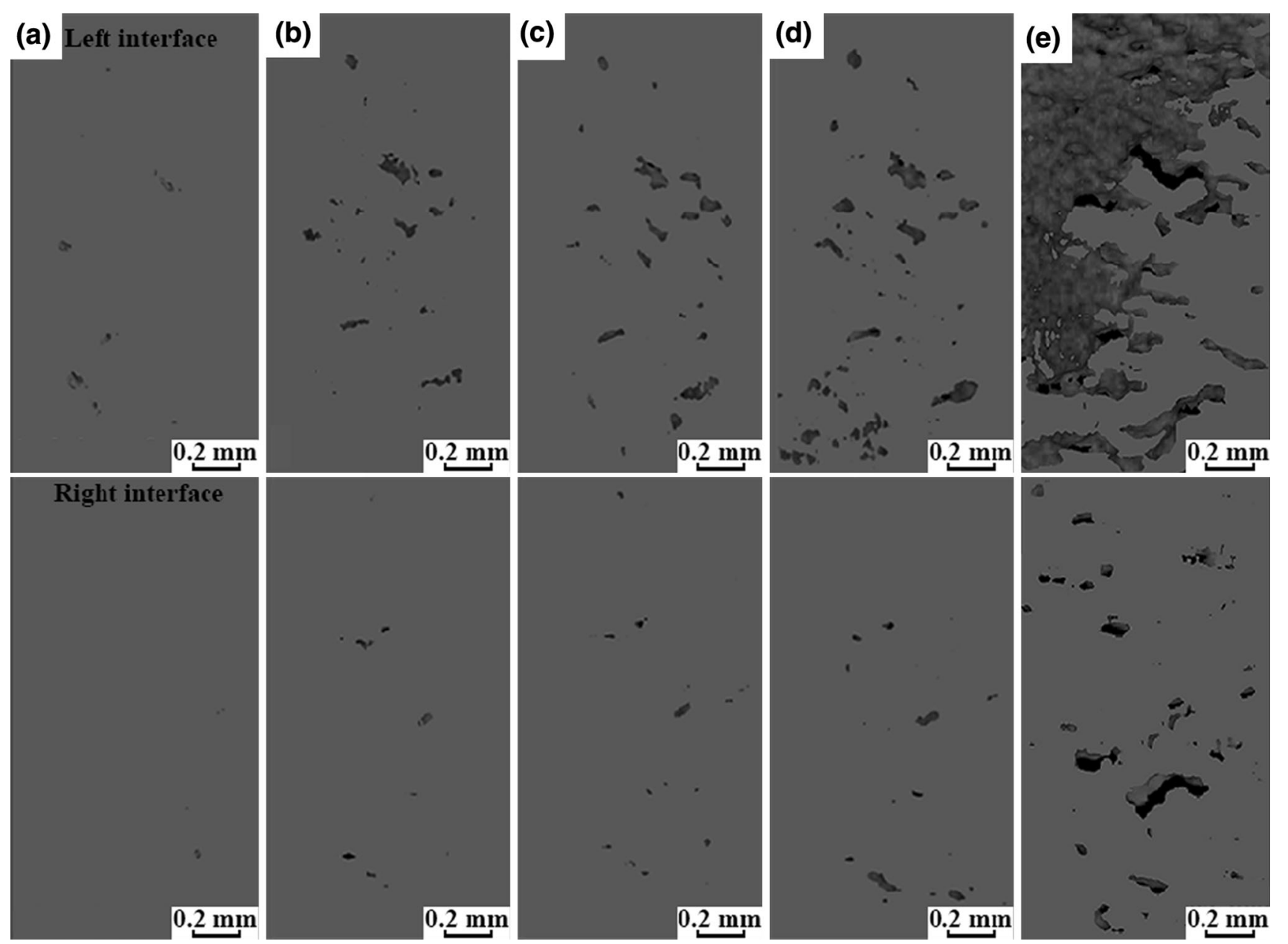

Fig. 13. Images of the two interfacial nano-silver paste layers (left interface and right interface) of specimen 2 at creep times of (a) $0 \mathrm{~h}$, (b) $5 \mathrm{~h}$, (c) $14 \mathrm{~h},(\mathrm{~d}) 18.5 \mathrm{~h}$, and (e) $24.5 \mathrm{~h}$.

interface than toward the right interface, as shown in Fig. 13. The connection and evolution of cracks at the left interface substantially reduced the effective loading area of the nano-silver sintered lap shear joint, thus increasing the local shear stress. The creep failure was accelerated significantly by the rapid growth of the cracks at the left interface, and as the local stress exceeded the shear fracture strength of the specimen, final fracture occurred at the left interface of specimen 2. Different crack growth paths led to a difference in creep life of $29.3 \mathrm{~h}$ for specimen 1 and $24.5 \mathrm{~h}$ for specimen 2 . By comparing the crack-growth processes of the two specimens it was found that the location and shape of the initial cracks affected the growth rate of the interfacial cracks, resulting in different creep lives, and were thus important in the creep process.

\section{Effect of Stress Level on Creep}

To reveal the effect of stress level on the creep of nano-silver sintered lap shear joints, specimen 1 was tested at a stress of $2 \mathrm{MPa}$ and $325^{\circ} \mathrm{C}$ and specimen 3 was tested at a stress of $3 \mathrm{MPa}$ and $325^{\circ} \mathrm{C}$. The strain-time relationship is given in Fig. 7. It was observed that the creep strain rate increased substantially with increasing stress level. Interfacial porosities were calculated to evaluate the crack growth at the interface. As shown in Fig. 12, the initial porosities of the left and right interfaces were $0.18 \%$ and $0.27 \%$, respectively, for specimen 1, compared with $0.13 \%$ and $0.45 \%$, respectively, for specimen 3. During the creep process, the porosities of the left and right interfaces developed synchronously with a higher stress greatly promoting growth of cracks. As a result, the life of specimen 1 at $2 \mathrm{MPa}$ was $29.3 \mathrm{~h}$ whereas that of specimen 3 at $3 \mathrm{MPa}$ was only approximately $6 \mathrm{~h}$.

\section{CONCLUSIONS}

As a porous die-attach material, nano-silver paste has much potential in wide-band-gap semiconductor systems. Creep behavior at elevated temperatures and low stress, which is of utmost importance to the reliability of nano-silver sintered lap shear joints, was considered in this study. Creep crack growth in the joints was characterized by non-destructive 
$\mathrm{x}$-ray 3D visualization technology. Creep fracture of the joint was a process of growth and coalescence of initial cracks along the nano-silver paste layers. The nano-silver lap shear joints had different initial cracks. The growth of initial cracks at the interfaces dominated the creep fracture process of nano-silver sintered lap shear joints. Initial interfacial crack characteristics, namely size, shape, and distribution, were important in the creep crack growth of the joint.

\section{ACKNOWLEDGEMENTS}

This study was supported by the National Natural Science Foundation of China (nos 11072171, 51401145, 51101112).

\section{REFERENCES}

1. M. Kerr and N. Chawla, Acta Mater. 52, 4527 (2004).

2. Y. Yang, Y.J.N. Balaraju, S.C. Chong, H. Xu, C.Q. Liu, V.V. Siberschmidt, and Z. Chen, J. Alloys Compd. 565, 11 (2013).

3. G.Q. Lu, S. Wen, X. Liu, J.N. Calata, and J.G. Bai, Solder Surf. Mount. Technol. 16, 27 (2004).

4. X. Li, G. Chen, L. Wang, Y.H. Mei, X. Chen, and G.Q. Lu, Mat. Sci. Eng. A Struct. 579, 108 (2013).

5. I. Duttan, J. Electron. Mater. 32, 201 (2003).

6. Z.Y. Zhang and G.Q. Lu, IEEE Trans. Electron. Pack. 25, $279(2002)$

7. J.G. Bai and G.Q. Lu, IEEE Trans. Dev. Mater. Reliab. 6, 436 (2006)

8. K. Maki, Y. Ito, H. Matsunaga, and H. Mori, Scr. Mater. 68, 777 (2013)

9. J.G. Bai, Z.Z. Zhang, J.N. Calata, and G.Q. Lu, IEEE Trans. Compon. Packag. Technol. 29, 589 (2006).

10. D.J. Yu, X. Chen, G. Chen, G.Q. Lu, and Z.Q. Zhang, Mater. Des. 30, 4574 (2009).

11. Y.H. Mei, G. Chen, G.Q. Lu, and X. Chen, Int. J. Adhes. Adhes. 35, 88 (2012).

12. T. Wang, X. Chen, G.Q. Lu, and G.L. Lei, J. Electron. Mater. 36,1333 (2007).

13. X. Chen, R. Li, K. Qi, and G.Q. Lu, J. Electron. Mater. 37, 1574 (2008).

14. T.G. Lei, J.N. Calata, G.Q. Lu, and G.Y. Lei, IEEE Trans. Compon. Packag. Technol. 3, 98 (2010).

15. G. Chen, X.H. Sun, P. Nie, Y.H. Mei, G.Q. Lu, and X. Chen, J. Electron. Mater. 41, 782 (2012).

16. R. Alizadeh, R. Mahmudi, and M.J. Esfandyarpour, Scr. Mater. 64, 442 (2011)
17. M.D. Mathew, H. Yang, S. Movva, and K.L. Murty, Metall. Mater. Trans. A 36, 99 (2005).

18. Q.K. Zhang and Z.F. Zhang, Scr. Mater. 67, 289 (2012).

19. C.H. Yu, C.W. Huang, C.S. Chen, Y. Gao, and C.H. Hsueh, Eng. Fract. Mech. 93, 48 (2012).

20. A.P. Alur, N. Chollacoop, and K.S. Kumar, Acta Mater. 55, 961 (2007).

21. K. Fakpan, Y. Otsuka, Y. Mutoh, S. Inoue, K. Nagata, and K. Kodani, J. Electron. Mater. 41, 2463 (2012).

22. K.I. Ohguchi, K. Sasaki, and M.J. Ishibashi, J. Electron. Mater. 35, 132 (2006).

23. M. Yatomi, K.M. Nikbin, and N.P. O'Dowd, Int. J. Press. Vessels Pip. 80, 573 (2003).

24. Y.M. Zhang, H.L. Zhu, M. Fujiwara, J.Q. Xu, and M. Dao, Scr. Mater. 68, 607 (2013).

25. R.J. McCabe and M.E. Fine, Metall. Mater. Trans. A 33, 1531 (2002).

26. M.L. Haung, L. Wang, and C.M.L. Wu, J. Mater. Res. 17, 2897 (2002).

27. H.A. Bale, A. Haboub, A.A. MacDowell, J.R. Nasiatka, D.Y. Parkinson, B.N. Cox, D.B. Marshall, and R.O. Ritchie, Nat. Mater. 12, 40 (2013).

28. M.A. Dudek, L. Hunter, S. Kranz, J.J. Williams, S.H. Lau, and N. Chawla, Mater. Charact. 61, 433 (2010).

29. J.C.E. Mertens, J.J. Williams, and N. Chawla, Mater. Charact. 92,36 (2014)

30. J.J. Williams, K.E. Yazzie, E. Padilla, N. Chawla, X. Xiao, and F. De Carlo, Int. J. Fatigue 57, 79 (2013).

31. P. Hruby, S.S. Singh, J.J. Williams, X.H. Xiao, F. De Carlo, and N. Chawla, Int. J. Fatigue 68, 136 (2014).

32. X. Li, G. Chen, X. Chen, G.Q. Lu, L. Wang, and Y.H. Mei, Microelectron. Reliab. 53, 174 (2013).

33. T. Reinikainen, M. Poech, M. Krumm, and J. Kivilahti, J. Electron. Pack. 120, 106 (1998).

34. N. Chawla, Y.L. Shen, X. Deng, and E.S. Ege, J. Electron. Mater. 33, 1589 (2004)

35. VAR, Inc., http://www.varian.com.

36. J.H. Kinney and M.C. Nichols, Annu. Rev. Mater. Sci. 22, 121 (1992).

37. S.S. Singh, C. Schwartzstein, J.J. Williams, X.H. Xiao, F. De Carlo, and N. Chawla, J. Alloys Compd. 602, 163 (2014)

38. E.Y. Guo, N. Chawla, T. Jing, S. Torquato, and Y. Jiao, Mater. Charact. 89, 33 (2014).

39. Y.S. Tan, X. Li, and X. Chen, Microelectron. Reliab. 54, 648 (2014).

40. Q. Yu, T. Shibutani, D. Kim, Y. Kobayashi, and J. Yang, Microelectron. Reliab. 48, 431 (2008).

41. L. Ladani and A. Dasgupta, J. Electron. Packag. 129, 273 (2007).

42. M.E. Kassner, Fundamentals of Creep in Metals and Alloys (Amsterdam: Elsevier, 2004).

43. E. Padilla, V. Jakkali, L. Jiang, and N. Chawla, Acta Mater. 60, 4017 (2012). 